\title{
UJI KESERAGAMAN DAN KESTABILAN BAK AIR SEBAGAI MEDIA KALIBRASI TERMOMETER TELINGA
}

\author{
Uniformity and Stability Test of Water Bath as Media Calibration for Ear Thermometer
}

\author{
Dwi Larassati ${ }^{1}$, Rahman Sholeh ${ }^{1}$, lip Ahmad Rifai ${ }^{1}$, Ghufron Zaid ${ }^{2}$, Melati Azizka Fajria ${ }^{1}$, Arfan \\ Sindhu' ${ }^{2}$, Suherlan ${ }^{1}$, Aditya Achmadi ${ }^{1}$, Muhammad Azumar ${ }^{1}$
}

${ }^{1}$ Pusat Riset dan Pengembangan SDM - BSN, Gd 420, Komplek Puspiptek Serpong

2Direktorat SNSU - BSN, Gd 430, Komplek Puspiptek Serpong

e-mail: dlarassati72@gmail.com

\begin{abstract}
Abstrak
Bak Air sebagai bagian dari sistem kalibrasi termometer telinga merupakan media yang telah didesain dengan dimensi persegi dengan ukuran luar $35 \mathrm{~cm} \times 25 \mathrm{~cm} \times 25 \mathrm{~cm}$ dan daerah kerja $16 \mathrm{~cm} \times 22 \mathrm{~cm} \times 22 \mathrm{~cm}$. Kontruksi dibuat menggunakan bahan stainless stell dan dikarakterisasi keseragaman dan kestabilannya. Karakterisasi dilakukan menggunakan 2 buah termometer tahanan platina standar dengan metode pengukuran axial dan metode pengukuran radial pada rentang suhu $35,5^{\circ} \mathrm{C}, 37,0^{\circ} \mathrm{C}$ dan $41,0 \stackrel{\circ}{\circ} \mathrm{C}$ didapatkan keseragaman terbesar 0,008 ${ }^{\circ} \mathrm{C}$, dan nilai stabilitas $0,017^{\circ} \mathrm{C}$. Dengan nilai tersebut bak air ini dapat dijadikan sebagai media kalibrasi yang merupakan bagian dari system kalibrasi thermometer telinga dan sudah memenuhi persyaratan sesuai OIML $R$ 7 , Edition 1979
\end{abstract}

Kata kunci: bak air, keseragaman, stabilitas, karakterisasi

\section{Abstract}

Water bath as part of the ear thermometer calibration system is a media that has been designed with square dimensions with an outer size of $35 \mathrm{~cm} \times 25 \mathrm{~cm} \times 25 \mathrm{~cm}$ and a working area of $16 \mathrm{~cm} \times 22 \mathrm{~cm} \times 22 \mathrm{~cm}$. Construction is made using stainless steel, and its uniformity and stability are characterized. Characterization was carried out using 2 standard platinum resistance thermometers with axial measurement methods and radial measurement methods in the temperature range of $35.5{ }^{\circ} \mathrm{C}, 37.0{ }^{\circ} \mathrm{C}$ and $41.0{ }^{\circ} \mathrm{C}$ obtained the greatest uniformity $0.008{ }^{\circ} \mathrm{C}$, and stability value $0.017^{\circ} \mathrm{C}$. With this value, this water bath can be used as a calibration media which is part of the ear thermometer calibration system and meets the requirements according to OIML $R$ 7, Edition 1979

Keywords: : water bath uniformity, stability, characterization

\section{PENDAHULUAN}

Pelayanan rumah sakit atau klinik diperlukan untuk melakukan pengobatan dan menjaga kesehatan pasiennya, dalam proses pengobatan diperlukan analisa awal salah satunya pengukuran kondisi suhu badannya. Alat ukur suhu yang populer digunakan saat ini adalah termometer telinga yang memiliki beberapa kelebihan yaitu higienis, mudah digunakan dan nilai pengukuran lebih mudah dibaca. Termometer telinga ini megukur suhu badan dengan metode pengukuran non kontak yaitu radiasi suhu didalam telinga. Untuk menjamin agar hasil pengukuran benar, akurat dan tertelusur diperlukan kalibrasi untuk memastikan alat yang digunakan dalam kondisi baik..

Dalam hal ini pemerintah melalui UndangUndang (UU) No. 36 tahun 2009 tentang kesehatan (Kesehatan, 2009), UU No. 44 tahun 2009 tentang rumah sakit, untuk dapat memenuhi persyaratan-persyaratan tersebut (Undangundang Rumah Sakit, 2009), Permenkes No. 54 Tahun 2015 Tentang Pengujian dan Kalibrasi Alat Kesehatan, mengatur bahwa alat-alat medis yang digunakan untuk keperluan diagnosa, terapi, rehabilitasi dan penelitian medik baik secara langsung maupun tidak langsung dan memiliki parameter penunjukan, keluaran, atau kinerja wajib untuk dikalibrasi atau diuji secara berkala (Permenkes No 54, 2015)

Saat ini kalibrasi termometer telinga masih belum dapat dilakukan dikarenakan keterbatasan peralatan yang dimiliki laboratorium laboratorium kalibrasi yang ada di Indonesia. Untuk itu kami melakukan penelitian melalui pendanaan INSINAS 2019 dengan judul. Pengembangan Sistem Kalibrasi Termometer Telinga Untuk Mendukung Standardisasi Bidang Kesehatan. Inti dalam sistem yang dibuat terdiri dari media kalibrasi, benda hitam (blackbody cavity), dan termometer standar. Salah satu komponen dari 
sistem ini adalah media kalibrasi berupa bak cairan., yang didisain dimensi, cairan bak dan pengaturan suhu agar mendapatkan nilai keseragaman dan stabilitas yang memenuhi syarat sebagai media kalibrasi termometer teinga. Penggunaan bak air untuk kalibrasi termometer telinga mesti memiliki kestabilan 0.02 $\stackrel{\circ}{ }$ dan keseragaman $0,01^{\circ} \mathrm{C}$ (OIML, 1979).

\section{TINJAUAN PUSTAKA}

Pengukuran suhu dilakukan dapat menggunakan termometer jenis non kontak dan kontak, (Nicholas \& White, 2001) yang termasuk jenis termometer non kontak yaitu termometer radiasi dan termometer telinga, sedangkan termometer jenis kontak contohnya termometer gelas, termometer tahanan platina,dan termometer digital dengan sensor.

Untuk mengkalibrasi termometer kontak dan non kontak diperlukan sebuah media kalibrasi dapat berupa bak cairan, drywell, mikrobath, tungku/furnace dan blackbody source. Sebagai media kalibrasi harus memilki sistem yang suhunya bisa diatur dan memiliki nilai keseragaman suhu yang baik.

Sistem kalibrasi termometer telinga yang dibangun merupakan gabungan dari pengukuran suhu kontak dan non kontak. Termometer termometer telinga merupakan termometer jenis non kontak yang dapat mengukur suhu radiasi dari objek ukurnya dalam hal ini diperlukan benda hitam atau blackbody cavity untuk mendapatkan sumber radiasi yang sangat teliti diperlukan pengkondisian blackbody cavity dalam sebuah bak cairan Desain yang diperlukan berupa bak cairan yang diyakini lebih baik dari stabilitas dan keseragamannya.

\subsection{Bak Cairan}

Bak cairan merupakan suatu alat atau wadah yang diisi cairan yang suhunya dapat diatur sesuai kebutuhan. Bak cairan memiliki beberapa komponen berupa pemanas (heater), pengontrol suhu, pengaduk (stirer) dan sensor suhu. Pemanas (heater) berfungsi untuk memanaskan cairan, pengontrol suhu berfungsi untuk mengatur suhu cairan dan pengaduk (stirer) berfungsi untuk mengaduk sehingga suhu cairan dalam bak menjadi seragam (Bentley, 1998)

Bak cairan menggunakan beberapa jenis cairan yang dapat digunakan sesuai rentang suhunya, jenis cairan yang umum digunakan yaitu alkohol atau etelin glykol $\left(-70^{\circ} \mathrm{C} \sim 25^{\circ} \mathrm{C}\right)$, air $\left(25^{\circ} \mathrm{C}\right.$ $\left.\sim 100^{\circ} \mathrm{C}\right)$, minyak silikon $\left(100^{\circ} \mathrm{C} \sim 300^{\circ} \mathrm{C}\right)$, dan garam campuran potassium nitrat (KNO3) dan sodium nitrat(NaNO3) dengan perbandingan 1:1 $\left(300^{\circ} \mathrm{C} \sim 650^{\circ} \mathrm{C}\right)$.

Semua jenis bak cairan ini yang dipasaran atau pabrikan biasanya sudah dilengkapi dengan data spesifikasi dari pembuat berupa nilai ketelitian / accuracy yang merupakan kualitas unjuk kerja dari bak cairan tersebut. Bak cairan digunakan sebagai media kalibrasi perlu dikarakterisasi keseragaman dan stabilitasnya. Nilai tersebut sebagai indikasi kualitas bak cairan tersebut, semakin kecil nilainya semakin baik kualitas bak cairan tersebut. Bak cairan yang didesain untuk Sistem kalibrasi termometer telinga merupakan bak air untuk rentang suhu $32^{\circ} \mathrm{C} \sim 42{ }^{\circ} \mathrm{C}$ dengan dimensi yang dibangun berbentuk persegi dengan ukuran luar $35 \mathrm{~cm} \times .25 \mathrm{~cm} \times 25 \mathrm{~cm}$ dan daerah kerja $16 \mathrm{~cm} \times .22 \mathrm{~cm}$ x $22 \mathrm{~cm}$.Kontruksi dibuat menggunakan bahan stainless steel, sistem pengadukan menggunakan motor agar suhu air merata. Berikut desain bak air gambar 1 .

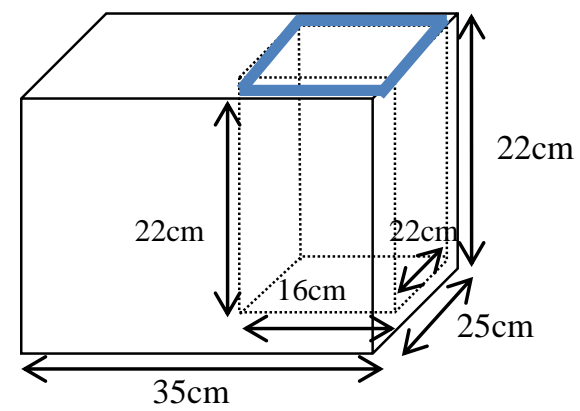

Gambar 1. Skema Desain Bak Cairan

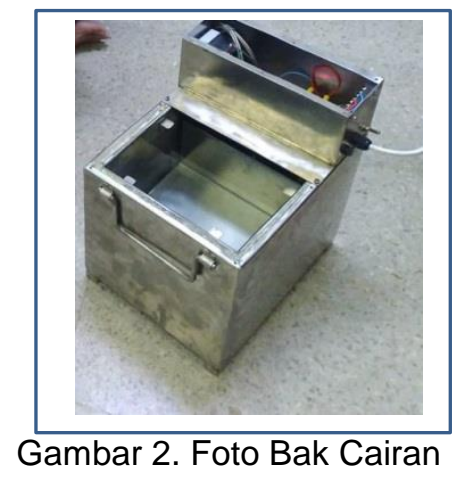

\subsection{Sistem Pengontrol Suhu}

Sistem pengontrol disusun oleh sensor dan aktuator yang melakukan tindakan tertentu untuk mengatur suatu proses sehubungan dengan beberapa spesifikasi (KA, C.O, A, \& A.O, 2013). Pengaturan suhu pada bak air menggunakan teknik pengaturan PID, yaitu dengan memproses signal suhu secara proporsional, integrasi, dan derivatif, sehingga suhu stabil pada suatu setpoint. 
Proporsional Band $(\mathrm{Pb})$ merupakan hal yang sangat mempengaruhi kestabilan suhu bak air. Rentang $\mathrm{Pb}$ berpangaruh terhadap kestabilan pengukuran suhu sebagaimana ditunjukkan pada gambar 3, apabila nilai proporsional band terlalu dekat maka suhu bak air akan berosilasi (berayun bolak balik) maksimal, hal ini dikarenakan kontroler bertindak berlebihan terhadap perubahan suhu. Apabila nilai proporsional band terlalu lebar maka suhu pada bak air tidak dapat stabil optimal karena kontroler kurang respon terhadap terjadinya perubahan suhu.

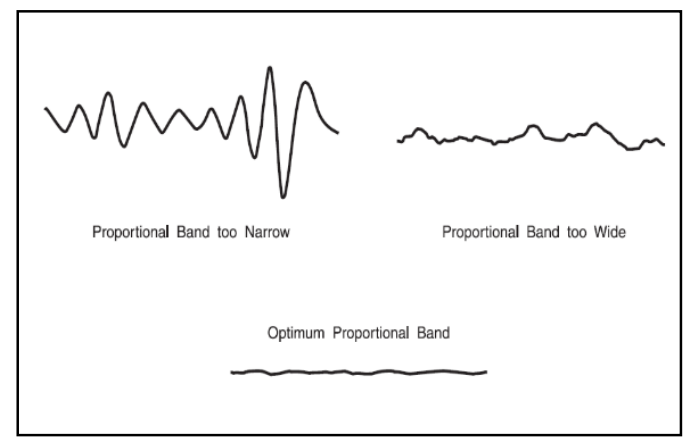

Gambar 3. Fluktuasi Suhu Bak Air akibat Variasi Setting $\mathrm{Pb}$

Proporsional Band yang optimum dipengaruhi oleh dimensi, volume air, sirkulasi, material yang dipanaskan, konduktivitas panas, setting power heater, dan suhu kerja. Nilai rentang proporsional band harus dikarakterisasi apabila terjadi perubahan pada faktor-faktor yang berpengaruh tersebut.

Sistem kontrol modern atau kontrol PID sebaiknya diset pada nilai terbaik dan nilai proporsional band dilakukan setting secara benar. Untuk sistem kontrol yang sensitif, sistem kontrol tersebut memiliki nilai gain besar dan nilai proporsional band kecil.

Bak Cairan yang dirancang sesuai gambar 1 , dilengkapi dengan sistem kendali suhu yan terdiri dari sistem pengontrol PID dan sensor suhu Pt100. Setting mode PID yaitu P:0,2 \% ; I :0\% dan D:15 detik. Berikut ditunjukkan Gambar 4. Skema pengendali suhu

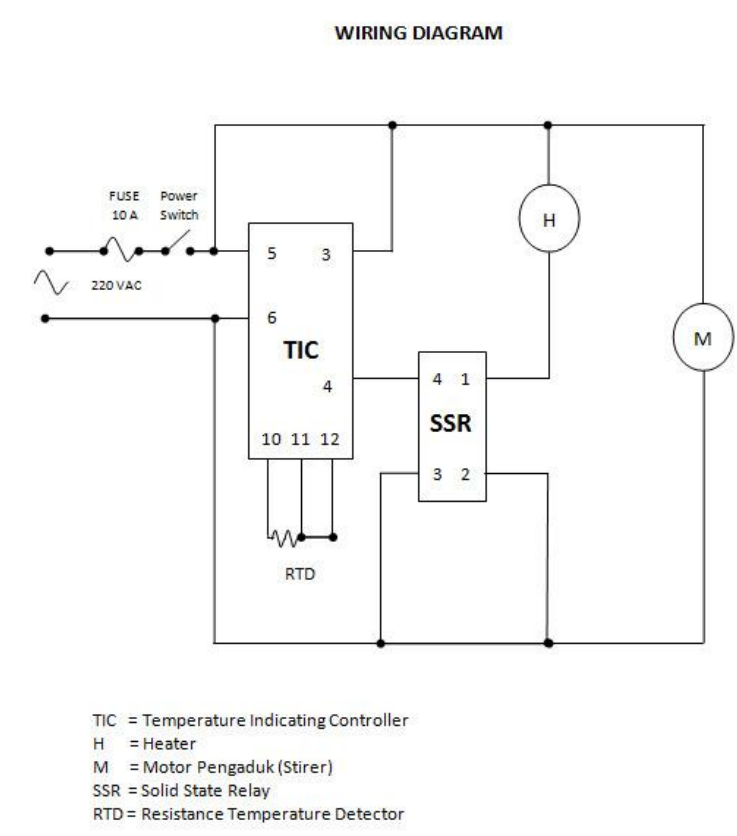

Gambar 4. . Skema Pengendali Suhu
(Autonics)

Prinsip kerja dari bak air adalah pada saat saklar ditekan pada posisi on, maka arus listrik dari sumber akan memberi suplai listrik pada heater. Heater yang diberi arus listrik akan memberikan panas pada air sehingga suhu air dalam bak semakin tinggi. Sensor suhu Pt-100 yang ditempatkan pada bak air akan mendeteksi suhu air. Pada derajat suhu tertentu sesuai setting pada pengontrol, sensor Pt-100 akan memberikan input kepada pengontrol.

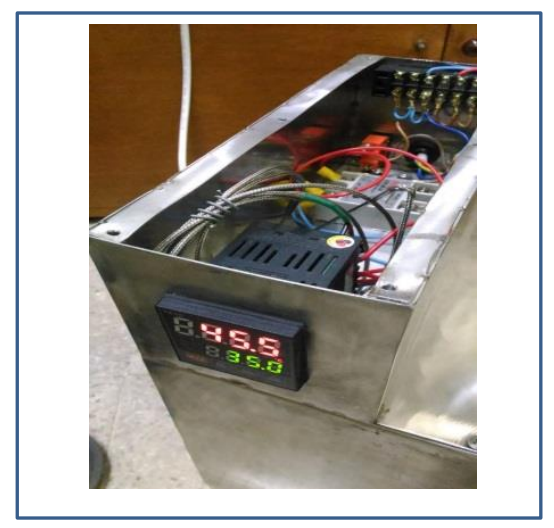

Gambar 5. Foto bagian dalam sistem kontrol bak air

Berdasarkan input dari Pt-100 tersebut maka pengontrol akan membuka kontaktor relay sehingga arus listrik terputus. Dengan demikian heater tidak mendapatkan suplai arus dan proses pemanasan akan berhenti. Suhu air dalam bak berangsur-angsur turun. Sensor Pt -100 akan 
mendeteksi suhu air dan memberikan input pada pengontrol untuk menutup kontaktor relay sehingga terjadi pemanas akan menyala dan pemanasan air kembali terjadi. Demikian seterusnya sehingga suhu air dalam bak konstan sesuai seting pada pengontrol

\section{METODE PENELITIAN}

Metode karakterisasi bak air ini menggunakan metode pengukuran secara Radial dan metode pengukuran secara Axial, menggunakan 2 buah termometer tahanan platina standar, sebuah indikator yang memiliki ketelitian tinggi dan sebuah computer untuk merekam hasil karakterisasi. Kedua sensor ditempatkan pada titik titik yang sudah ditentukan 5 posisi berdasarkan daerah kerja yang akan digunakan (ASTM, 2011)
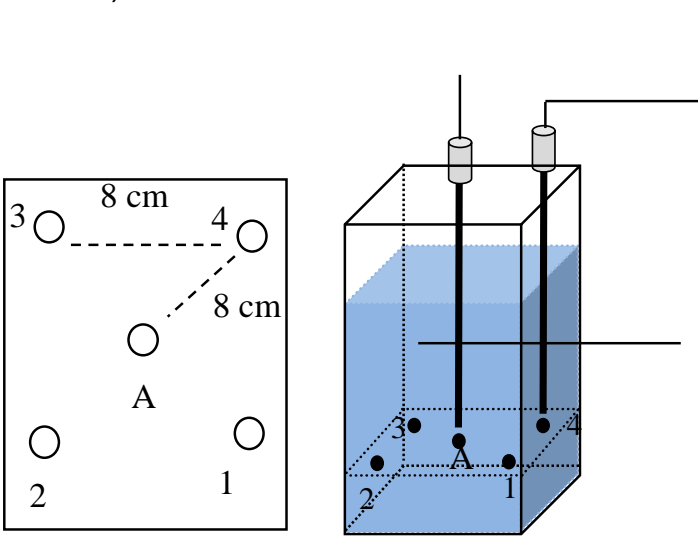

Gambar 6. Sistem Pengukuran Secara Radial

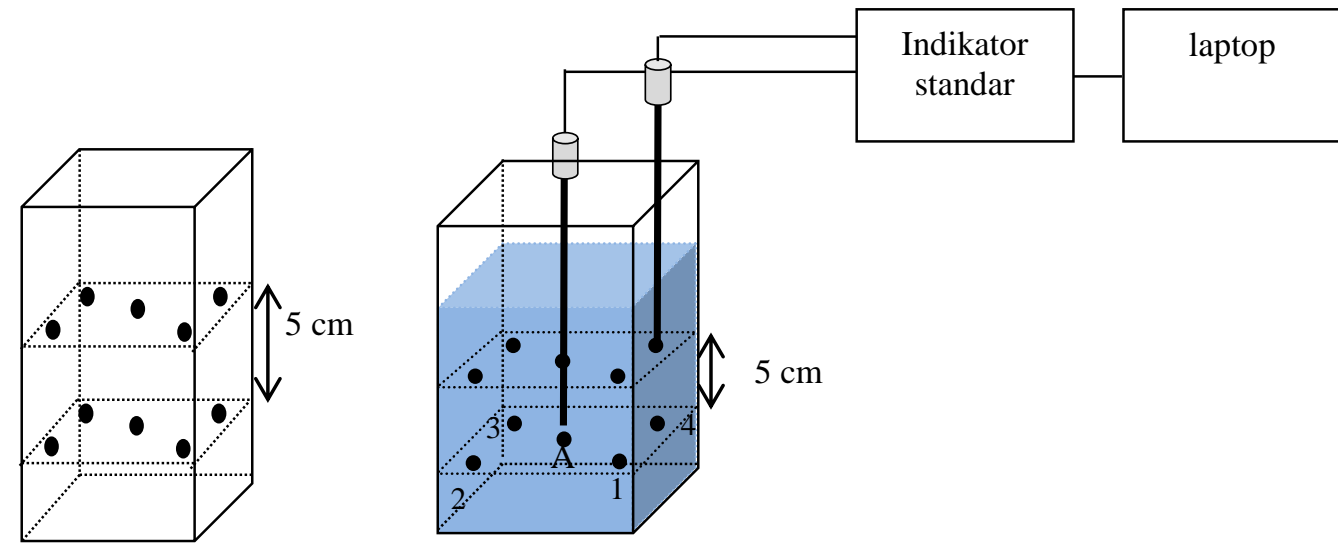

Gambar 7. Sistem Pengukuran Secara Axial

\subsection{Pengukuran secara Axial}

Pemindahan Sensor pada pengambilan data ditarik ke atas (vertical) pada posisi yang telah ditentukan sesuai gambar 2 .

Pengambilan data dilakukan setelah bak cairan sudah stabil sesuai setting suhunya dengan cara

\subsection{Pengukuran Secara Radial}

Pengukuran dilakukan dengan cara pemindahan sensor termometer tahanan platina pengukur (TTP2) secara horizontal ke posisi sesuai dengan gambar 5 , dan posisi termometer tahanan platina acuan (TTP1) ditempatkan pada posisi yang tetap (posisi A).

Pengambilan data dilakukan setelah bak air sudah stabil sesuai setting suhunya dengan cara dibandingkan penunjukkan TTP1 (acuan) pada posisi A dan TTP2 posisi 1,. selanjutnya TTP2 dipindahkan ke posisi 2, 3 dan 4, sehingga dalam satu set pengukuran untuk kedalaman sensor 15 cm mempunyai 4 pasang data : A-1, A-2, A-3 dan A-4,

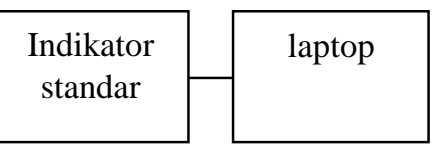


Uji Keseragaman dan Kestabilan Bak Air Sebagai Media Kalibrasi Termometer Telinga (Dwi Larassati, Rahman Sholeh, lip Ahmad Rifai, Ghufron Zaid, Melati Azizka Fajria, Arfan Sindhu, Suherlan, Aditya Achmadi, Muhammad Azumar)
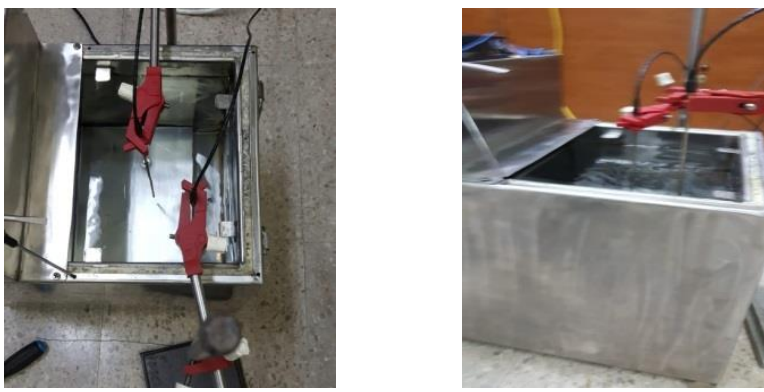

Gambar 8 . Foto karakterisasi Bak Air

\section{HASIL DAN ANALISA}

Karakterisasi bak air dilakukan pada titik $35,5^{\circ} \mathrm{C}$ $37,0^{\circ} \mathrm{C}$, dan $41,0^{\circ} \mathrm{C}$. (ASTM E 667 - 98, 2003) Pengukuran dilakukan dengan 2 buah : TTP 1 merk ISOTECH tipe 935-14-112 No.Seri : 393092 dan TTP 2 merk ISOTECH tipe 935-14-112 No.Seri : 39309-2 yang tertelusur ke SNSU BSN yang memilki ketidakpastian $0,03^{\circ} \mathrm{C}$ dengan factor cakupan 2.Titk titik posisi disesuaikan dengan gambar 6 dan gambar 7, berikut hasil pengukuran keseragaman bak air.

Tabel 1. Data Pengukuran Keseragaman setting suhu $35,5^{\circ} \mathrm{C}$

\begin{tabular}{|c|c|c|c|c|}
\hline $\begin{array}{c}\text { Kedalaman } \\
\text { pengukuran }\end{array}$ & \multirow{2}{*}{ Posisi titik Ukur } & \multicolumn{2}{|c|}{ Penunjukkan ${ }^{\circ} \mathrm{C}$} & \multicolumn{1}{c|}{$\Delta \mathrm{t}$} \\
\cline { 3 - 5 } & & Acuan TTP1 & TTP2 & ${ }^{\circ} \mathrm{C}$ \\
\hline \multirow{5}{*}{$10 \mathrm{~cm}$} & $\mathrm{~A}-1$ & 35.65924511 & 35.66502332 & 0.006 \\
\cline { 2 - 5 } & $\mathrm{A}-2$ & 35.66102643 & 35.66586712 & 0.005 \\
\cline { 2 - 5 } & $\mathrm{A}-3$ & 35.67495199 & 35.67478633 & 0.000 \\
\cline { 2 - 5 } & $\mathrm{A}-4$ & 35.66184522 & 35.66705468 & 0.005 \\
\hline \multirow{4}{*}{$15 \mathrm{~cm}$} & $\mathrm{~A}-\mathrm{B} 1$ & 35.65625749 & 35.66099186 & 0.005 \\
\cline { 2 - 5 } & $\mathrm{A}-\mathrm{B} 2$ & 35.65284486 & 35.66070435 & 0.008 \\
\cline { 2 - 5 } & $\mathrm{A}-\mathrm{B} 3$ & 35.65547621 & 35.65904176 & 0.004 \\
\cline { 2 - 5 } & $\mathrm{A}-\mathrm{B} 4$ & 35.63971933 & 35.64667862 & 0.007 \\
\hline
\end{tabular}

Nilai keseragaman diambil dari table 1 merupakan selisih penunjukkan nilai TTP 1 (Acuan) pada posisi A dengan penunjukkan TTP 2 pada setiap posisi titik ukur berdasarkan pengukuran axial dan pengukuran radial. Nilai yang diambil dari nilai selisih terbesar di pengukuran posisi $A$ dan $B 2$ yaitu $0,008^{\circ} \mathrm{C}$

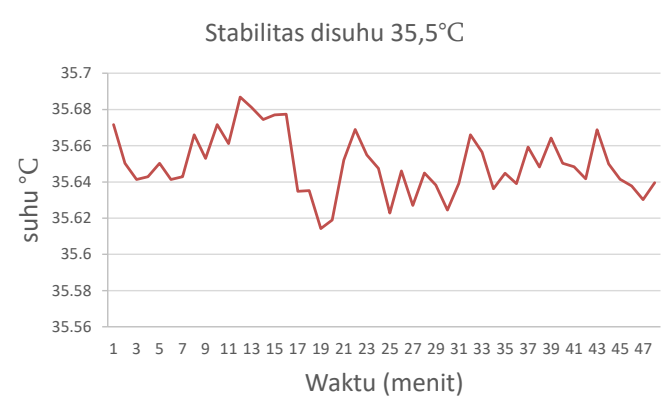

Gambar 9 . Hasil Pengukuran stabilitas pada suhu $35,5^{\circ} \mathrm{C}$
Pengukuran stabilitas diambil dari nilai standar deviasi terbesar penunjukkan TTP1 atau Acuan. Pengukuran kestabilan dilakukan selama 30 menit pada semua posisi titik ukur nya, nilai stabilitas pada suhu $35,5^{\circ} \mathrm{C}$ adalah $0,017^{\circ} \mathrm{C}$.

Tabel 2. Data Pengukuran Keseragaman setting suhu $37,0^{\circ} \mathrm{C}$

\begin{tabular}{|c|c|c|c|c|}
\hline \multirow{2}{*}{$\begin{array}{l}\text { Kedalaman } \\
\text { pengukuran }\end{array}$} & \multirow{2}{*}{ Posisi titik } & \multicolumn{2}{|c|}{ Penunjukkan ${ }^{\circ} \mathrm{C}$} & \multirow{2}{*}{$\begin{array}{l}\Delta \mathrm{t} \\
{ }^{\circ} \mathrm{C} \\
\end{array}$} \\
\hline & & Acuan TTP1 & TTP2 & \\
\hline \multirow{4}{*}{$10 \mathrm{~cm}$} & A-1 & 37.162823 & 37.157264 & 0.006 \\
\hline & A-2 & 37.182993 & 37.176540 & 0.006 \\
\hline & A-3 & 37.149263 & 37.142517 & 0.007 \\
\hline & $\overline{A-4}$ & 37.171639 & 37.167562 & 0.004 \\
\hline \multirow[t]{4}{*}{$15 \mathrm{~cm}$} & A-B1 & 37.170317 & 37.165646 & 0.005 \\
\hline & A-B2 & 37.126168 & 37.119010 & 0.007 \\
\hline & A-B3 & 37.165108 & 37.156793 & 0.008 \\
\hline & A-B4 & 37.164620 & 37.161999 & 0.003 \\
\hline
\end{tabular}

Nilai keseragaman diambil dari table 2 merupakan selisih penunjukkan nilai TTP 1(Acuan) pada posisi A dengan penunjukkan TTP 2 pada setiap posisi titik ukur berdasarkan pengukuran axial dan pengukuran radial. Nilai yang diambil dari nilai selisih terbesar di pengukuran posisi $\mathrm{A}$ dan $\mathrm{B} 2$ yaitu $0,008^{\circ} \mathrm{C}$

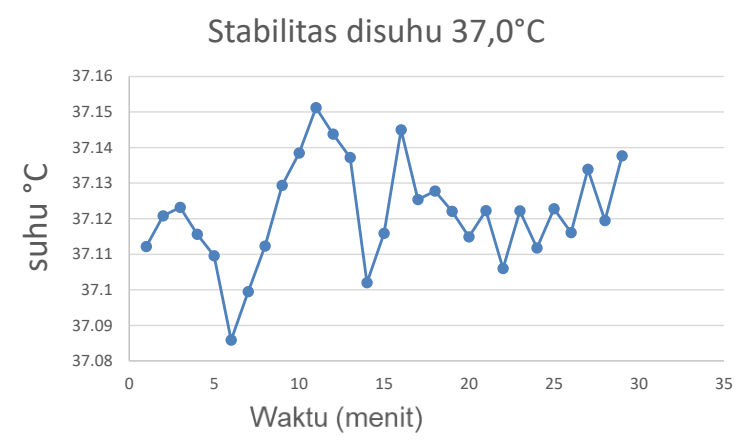

Gambar 10 . Hasil Pengukuran stabilitas pada suhu $37,0^{\circ} \mathrm{C}$

Pengukuran stabilitas diambil dari nilai standar deviasi terbesar penunjukkan TTP1 atau Acuan. Pengukuran kestabilan dilakukan selama 30 menit pada semua posisi titik ukur nya, nilai stabilitas pada suhu $37,0^{\circ} \mathrm{C}$ adalah $0,014^{\circ} \mathrm{C}$.

Tabel 3. Data Pengukuran Keseragaman setting suhu $41,0^{\circ} \mathrm{C}$

\begin{tabular}{|c|c|r|c|c|}
\hline \multirow{2}{*}{$\begin{array}{c}\text { Kedalaman } \\
\text { pengukuran }\end{array}$} & Posisi titik & \multicolumn{2}{|c|}{ Penunjukkan ${ }^{\circ} \mathrm{C}$} & $\Delta \mathrm{t}$ \\
\cline { 3 - 4 } & & Acuan TTP1 & \multicolumn{1}{c|}{ TTP2 } & ${ }^{\circ} \mathrm{C}$ \\
\hline \multirow{5}{*}{$10 \mathrm{~cm}$} & $\mathrm{~A}-1$ & 41.642095 & 41.648220 & 0.006 \\
\hline & $\mathrm{A}-2$ & 41.665296 & 41.671283 & 0.006 \\
\hline & $\mathrm{A}-3$ & 41.623576 & 41.631020 & 0.007 \\
\hline & $\mathrm{A}-4$ & 41.668978 & 41.675246 & 0.006 \\
\hline \multirow{2}{*}{$15 \mathrm{~cm}$} & $\mathrm{~A}-\mathrm{B} 1$ & 41.635539 & 41.642095 & 0.006 \\
\hline & $\mathrm{A}-\mathrm{B} 2$ & 41.646220 & 41.651889 & 0.007 \\
\hline & $\mathrm{A}-\mathrm{B} 3$ & 41.658958 & 41.666202 & 0.007 \\
\hline & $\mathrm{A}-\mathrm{B} 4$ & 41.658958 & 41.666202 & 0.007 \\
\hline
\end{tabular}

Nilai keseragaman diambil dari table 3 merupakan selisih penunjukkan nilai TTP 1 
(Acuan) pada posisi A dengan penunjukkan TTP 2 pada setiap posisi titik ukur berdasarkan pengukuran axial dan pengukuran radial. Nilai yang diambil dari nilai selisih terbesar di pengukuran posisi $\mathrm{A}$ dan $\mathrm{B} 2$ yaitu $0,007^{\circ} \mathrm{C}$

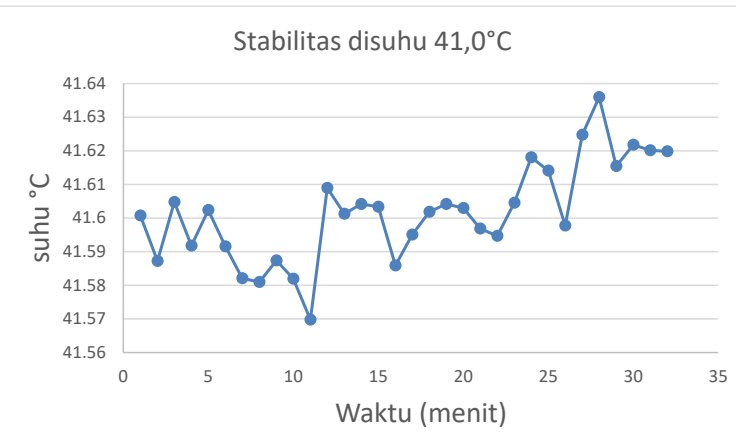

Gambar 11. Hasil Pengukuran stabilitas pada suhu $41,0^{\circ} \mathrm{C}$

Pengukuran stabilitas diambil dari nilai standar deviasi terbesar penunjukkan TTP1 atau Acuan. Pengukuran kestabilan dilakukan selama 30 menit pada semua posisi titik ukurnya, nilai stabilitas pada suhu $41,0^{\circ} \mathrm{C}$ adalah $0,015^{\circ} \mathrm{C}$

\section{KESIMPULAN}

Hasil karakterisasi diambil dari semua pengukuran berdasarkan posisi daerah kerja bak air dengan metode pengukuran axial dan radial didapatkan nilai keseragaman pada suhu $35,5^{\circ} \mathrm{C}$ : $0,08^{\circ} \mathrm{C}, 37,0^{\circ} \mathrm{C}: 0,008^{\circ} \mathrm{C}, 41,0^{\circ} \mathrm{C}: 0,007^{\circ} \mathrm{C}$, untuk kestabilan pada $35,5^{\circ} \mathrm{C}: 0,017^{\circ} \mathrm{C}, 37,0^{\circ} \mathrm{C}$ : $0,014^{\circ} \mathrm{C}, 41,0^{\circ} \mathrm{C}: 0,015^{\circ} \mathrm{C}$

Nilai keseragaman dan kestabilan yang didapatkan dari hasil karakterisasi masuk dengan yang dipersyaratkan pada OIML - R7, bak air yang dibuat dapat dijadikan media kalibrasi untuk sistem kalibrasi thermometer telinga

\section{UCAPAN TERIMAKASIH}

Terima kasih Pengelola Pendanaan INSINAS 2019 , kepada Bapak Acep Sujita AMD, Arlan,ST. Efendi, ST. selaku tim teknisi ke laboratorium metrologi suhu atas bantuannya sehingga penelitian ini dapat terlaksana dengan baik

\section{DAFTAR PUSTAKA}

ASTM. (2011). Standard Spesification fo Gravity Convection and Forced-Clrculation Water Bath. ASTM.

ASTM E 667 - 98. (2003). Standard Spesification for mercury-in-Glass Maximum SelfRegistering CLinical Thermometer.
Autonics. (n.d.). High Accuracy PID Temperature Controller TK4 Series Instruction Manual. Autonics.

Bentley, R. E. (1998). Resitance and Liquid-inGlass Thermoetry. In Handbook of Temperature Measurement Vol 2.

KA, A., C.O, E., A, E., \& A.O, N. (2013). Design,Modelling and Slmulation of Microcontrole Based Temperature Controller in Ventilation. IJREEIE.

Kesehatan, K. (2009). Undang-Undang No 36. Kemetrian Kesehatan.

Nicholas, J. V., \& White, D. R. (2001). In Treceable Temperature (An Introduction to Temperature Measurement \& Calibration).

OIML. (1979). Clinical Thermometer (Mercury-inglass, WIth Maximum Device). OIML R7.

Permenkes No 54. (2015). Pengujian dan Kalibrasi Alat Kesehata. Kementrian Kesehatan.

Undang-undang Rumah Sakit. (2009). Undang Undang No 14 Tentang Rumah Sakit. Kementrian Kesehatan. 